\title{
Sexual Functioning after Stroke among Rehabilitation Medicine Out-Patients and their Sexual Partners: A Cross-Sectional Study
}

\author{
Carl Froilan D. Leochico, ${ }^{1,2}$ Jose Alvin P. Mojica, ${ }^{1}$ Sharon D. Ignacio ${ }^{1}$ and Betty Dy-Mancao ${ }^{1}$ \\ ${ }^{1}$ Department of Rehabilitation Medicine, College of Medicine and Philippine General Hospital, University of the Philippines Manila \\ ${ }^{2}$ Physical Medicine and Rehabilitation Department, St. Luke's Medical Center, Quezon City
}

\begin{abstract}
Background. Sexuality remains to be a sensitive issue in the Philippines, but it encompasses real problems that stroke patients and their partners continue to face. Sexual dysfunction, an under-recognized complication poststroke, is caused by an interplay of physical, emotional, cognitive, and language impairments, in combination with psychosocial factors.

Objectives. This study aimed to determine changes in sexual functioning (libido, coital frequency, sexual arousal, and sexual satisfaction) among stroke out-patients at the Philippine General Hospital and their sexual partners.

Methods. This cross-sectional study involved patients ( $\geq 30$ years old with 1 stroke episode), and their partners. Through individual interviews and questionnaires, data were gathered on general attitude toward sex, ability to address sexual issues with partner, fear of recurrence of stroke, unwillingness to participate in coitus, risk of depression, and level of happiness.
\end{abstract}

Results. Twenty-nine patients and 23 partners participated. There was a statistically significant decrease in coital frequency post-stroke among patients $(p<0.001)$ and partners $(p<0.05)$. Majority reported lower level of libido, sexual arousal, and sexual satisfaction post-stroke. Participants unable to discuss sexual issues with partner were more likely to report sexual dissatisfaction $(p<0.05)$. Those with higher scores on Zung's depression scale were likely to be sexually dissatisfied $(p<0.05)$. Level of happiness was moderately correlated with sexual satisfaction $(r=0.51)$.

Conclusion. Sexual life of couples affected by stroke is commonly overlooked. There was a decline in libido, coital frequency, arousal, and sexual satisfaction among stroke patients and partners at the Philippine General Hospital.

Key Words: stroke rehabilitation, sexuality, sexual partners

Paper was presented and won $1^{\text {st }}$ place at the Research Forum of the Philippine Academy of Rehabilitation Medicine $27^{\text {th }}$ Annual Convention, February 16, 2017, Conrad Hotel, Pasay City, Philippines.

Poster was presented at the 13th International Society of Physical and Rehabilitation Medicine World Congress, June 9-13, 2019, Kobe, Japan.

Corresponding author: Carl Froilan D. Leochico, MD, PTRP

Department of Rehabilitation Medicine

Philippine General Hospital

University of the Philippines Manila

Taft Avenue, Manila 1000, Philippines

Email: cfdleochico0902@gmail.com

\section{INTRODUCTION}

The American Stroke Association, Stroke Society of the Philippines, and Philippine Academy of Rehabilitation Medicine recognize sexual dysfunction as a complication that must be addressed after stroke. ${ }^{1-3}$ Sexual dysfunction post-stroke may manifest as decrease in libido and coital frequency, decline in vaginal lubrication and orgasm among women, or erectile dysfunction and/or failed ejaculation among men, and dissatisfaction in sexual life. ${ }^{4}$ According to the study of Korpelainen et al., the changes in libido and coital habits were found to be significantly associated with physical, psychological, and social factors: 1) Physical factors: as reflected in the degree of functional disability $(\mathrm{p}=0.005), 2)$ Psychological factors: as shown by the patients' general attitude toward sexuality $(\mathrm{p}<0.001)$, and their 
unwillingness to participate in sexual activity $(\mathrm{p}<0.001)$, and 3) Social factors: as manifested by difficulty in discussing sexuality with their spouse $(\mathrm{p}<0.001) .{ }^{5}$ Other psychological factors, such as loss of self-esteem, depression, and fear of not pleasing their sexual partners, were also explored in the study.

The sexual problems experienced by stroke patients and their partners remain to be of significant magnitude and frequency to warrant local investigation, which should include possible causative factors. ${ }^{5-8}$ Sexual partners are as important as the patients with regard to the holistic care of stroke patients. A limited body of research on the quality of sexual life of spouses, who are usually the primary caregivers, suggests that there may occur a parallel decline in sexual functioning between patients and their spouses. 4,5 The interplay of physical, emotional, and cognitive and/or language impairments, in combination with psychosocial issues, following stroke can be overwhelming for patients and their partners, with profound effects on intimacy and sexuality.

This study aimed to determine changes in sexual functioning after stroke among out-patients seen at the Philippine General Hospital and their sexual partners in terms of the following outcomes: 1) libido, 2) coital frequency, 3) sexual arousal, specifically, erectile ability (among males) or vaginal lubrication and orgasmic ability (among females), and 4) sexual satisfaction.

\section{METHODS}

\section{Study Design and Population}

This cross-sectional study included adult patients $\geq 30$ years old who had one incident of stroke (regardless of etiology, type, and location and laterality of brain lesion) more than 2 months prior to recruitment, confirmed by cranial computed tomography scan and/or magnetic resonance imaging, seeking consult at the Out-Patient Department of the Department of Rehabilitation Medicine, Philippine General Hospital. We included patients who had 1 sexual partner of the opposite sex. Patients with 2 or more strokes, global or Wernicke's aphasia, inability to communicate or express thoughts, and absence of sexual partner or spouse were excluded from the study.

The sample size was computed based on the department's census (96 new stroke cases in 6 months). Using Open Source Calculator (OpenEpi Version 3), the population size was entered as 96, along with the following pre-set parameters: $95 \%$ confidence interval, $50 \pm 5 \%$ hypothesized $\%$ frequency of outcome factor in the population, and design effect of 1 . The computed sample size was 78 participants (39 stroke patients and 39 sexual partners).

\section{Procedure}

After voluntary, written, informed consent was secured from both patient and sexual partner, each participant underwent a semi-structured interview separately in a private room, where a psychologist sat in to detect any psychological issue that might arise, and to further evaluate and manage it accordingly after the interview. A data collection form, containing three parts, was used during the interview: (1) demographic and clinical characteristics; (2) questions on general attitudes towards sexual intercourse, ability to address sexual issues with partner, fear of recurrence of stroke, and willingness to participate in sexual intercourse; and (3) questions on changes in libido, coital frequency, erectile/ orgasmic ability, and satisfaction with sexual life, which were modified based on the study by Monga et al. ${ }^{4}$ After the interviews, participants were asked to answer two self-administered questionnaires: 1) Zung's Depression Scale, and 2) Happiness Scale. ${ }^{9-11}$ The questionnaires and guidelines for the semi-structured interview $^{12}$ were translated to Filipino, subjected to pre-test, and face validity was established.

\section{Ethical Considerations}

The study was approved by the Technical Review Board of the Department of Rehabilitation Medicine and by the University of the Philippines Manila Research Ethics Board prior to data collection. It was conducted according to the Good Clinical Practice Guidelines and in full conformity to the Declaration of Helsinki (2008). The participants were oriented as to study objectives, procedure, benefits, hazards, and sensitive issues that were involved in the study. At any time during data collection, they were allowed to freely withdraw from the study. All data were kept private and confidential. The investigators had no conflict of interests to declare.

\section{Treatment of Data}

Descriptive and analytical tests were performed using Open Source Calculator (OpenEpi Version 3) and Microsoft Excel version 14.0. The t-test for independent samples was used to determine the statistical difference between patients' and partners' reported time of resumption of sexual intercourse post-stroke, and the difference in Zung's Depression Scale scores between the sexually satisfied and sexually dissatisfied groups. Meanwhile, t-test for paired samples was used to determine the difference in coital frequency pre- and post-stroke. Fisher's exact test and chi-square test were used to determine the difference in psychosocial factors between the sexually satisfied and sexually dissatisfied groups. Pearson's correlation coefficient was used to determine the relationship between happiness and sexual satisfaction. The strength of association for absolute values of $r$ was defined as follows: 0.00-0.19 (very weak), $0.20-0.39$ (weak), 0.40-0.59 (moderate), $0.60-0.79$ (strong), and $0.80-$ 1.00 (very strong correlation). ${ }^{13}$ All data were presented and analyzed at $95 \%$ confidence interval. 


\section{RESULTS}

Out of 96 new (initial) and old (follow-up) cases of stroke seen at the Department of Rehabilitation Medicine Philippine General Hospital in a span of 6 months, 52 participants were recruited, consisting of 29 stroke patients and 23 sexual partners. The other 6 partners were considered drop-outs due to their unavailability or difficulty in leaving work or home. The demographic and clinical characteristics of the participants are presented in Table 1.

Sexuality was defined by participants in a variety of ways. The most common definitions pertained to the importance of sexual intercourse in married life $(n=19)$, inherent human need $(\mathrm{n}=14)$, companionship $(\mathrm{n}=10)$, and a

Table 1. Characteristics of study population

\begin{tabular}{|c|c|c|c|}
\hline Characteristics & $\begin{array}{l}\text { Stroke Patients } \\
\qquad N=29\end{array}$ & $\begin{array}{l}\text { Sexual Partners } \\
\qquad N=23\end{array}$ & $\begin{array}{l}\text { All Participants } \\
\quad \mathrm{N}=52\end{array}$ \\
\hline \multicolumn{4}{|l|}{ 1. Demographic factors } \\
\hline Age & $51.7 \pm 8.4$ & $49.3 \pm 8.4$ & $50.7 \pm 8.5$ \\
\hline \multicolumn{4}{|l|}{ Sex } \\
\hline Males & $19(65.5)$ & $8(34.8)$ & $27(51.9)$ \\
\hline Females & $10(34.5)$ & $15(65.2)$ & $25(48.1)$ \\
\hline \multicolumn{4}{|l|}{ Civil status } \\
\hline Single & $5(17.2)$ & $5(21.7)$ & $10(19.2)$ \\
\hline Married & $22(75.9)$ & $18(78.3)$ & $40(76.9)$ \\
\hline Separated & $0(0.0)$ & $0(0.0)$ & $0(0.0)$ \\
\hline Widow/er & $2(6.9)$ & $0(0.0)$ & $2(3.8)$ \\
\hline \multicolumn{4}{|l|}{ 2. Clinical factors } \\
\hline Duration of stroke, yrs $(n=29)$ & $7.3 \pm 5.2$ & N/A & $7.3 \pm 5.2$ \\
\hline \multicolumn{4}{|l|}{ Type of stroke $(n=29)$} \\
\hline Ischemic & $24(82.8)$ & N/A & $24(82.8)$ \\
\hline Hemorrhagic & $5(17.2)$ & N/A & $5(17.2)$ \\
\hline \multicolumn{4}{|l|}{ Laterality of brain lesion $(n=29)$} \\
\hline Right & $13(44.8)$ & N/A & $13(44.8)$ \\
\hline Left & $16(55.2)$ & N/A & $16(55.2)$ \\
\hline \multicolumn{4}{|l|}{ Comorbidity $(n=52)$} \\
\hline Coronary artery disease & $7(13.5)$ & $0(0.0)$ & $7(13.5)$ \\
\hline Diabetes mellitus & $9(75.0)$ & $3(13.0)$ & $12(23.1)$ \\
\hline Hypertension & $27(93.1)$ & $10(43.5)$ & $37(71.2)$ \\
\hline $\begin{array}{l}\text { Others (Benign prostatic hyperplasia, Anemia, Osteoarthritis, } \\
\text { Osteoporosis, Bronchial asthma, Cancer) }\end{array}$ & $7(24.1)$ & $3(13.0)$ & $10(19.2)$ \\
\hline \multicolumn{4}{|l|}{ Medications $(n=52)$} \\
\hline Anti-convulsants & $10(19.2)$ & $10(19.2)$ & $10(19.2)$ \\
\hline Anti-depressants & $7(13.5)$ & $7(13.5)$ & $7(13.5)$ \\
\hline \multicolumn{4}{|l|}{ Anti-hypertensives } \\
\hline Beta-blockers & $1(3.4)$ & $1(4.3)$ & $2(3.8)$ \\
\hline Calcium channel blockers & $24(82.8)$ & $4(17.4)$ & $28(53.8)$ \\
\hline Angiotensin II - receptor blockers & $28(96.6)$ & $3(13.0)$ & $31(59.6)$ \\
\hline \multicolumn{4}{|l|}{ Alterations in body structure \& function $(n=29)$} \\
\hline Altered tone & $25(86.2)$ & N/A & $25(86.2)$ \\
\hline Hemiplegia/ hemiparesis & $28(96.6)$ & N/A & $28(96.6)$ \\
\hline Hemisensory symptoms & $18(62.1)$ & N/A & $18(62.1)$ \\
\hline Aphasia & $2(6.9)$ & N/A & $2(6.9)$ \\
\hline Balance problems & $6(20.7)$ & N/A & $6(20.7)$ \\
\hline Endurance problems & $4(13.8)$ & N/A & $4(13.8)$ \\
\hline \multicolumn{4}{|l|}{ Alterations in activity $(n=29)$} \\
\hline \multicolumn{4}{|l|}{ Modified Rankin Scale (degree of disability) } \\
\hline No symptoms (0) & $1(3.4)$ & N/A & $1(3.4)$ \\
\hline No disability (1) & $9(31.0)$ & N/A & $9(31.0)$ \\
\hline Slight disability (2) & $18(62.1)$ & N/A & $18(62.1)$ \\
\hline Moderate disability (3) & $1(3.4)$ & N/A & $1(3.4)$ \\
\hline Moderately severe to severe disability (4-5) & $0(0.0)$ & N/A & $0(0.0)$ \\
\hline \multicolumn{4}{|l|}{ Personal Factors $(\mathrm{n}=52)$} \\
\hline Zung's Self-Rating Depression Scale score & $38.0 \pm 7.7$ & $32.3 \pm 7.7$ & $35.5 \pm 8.1$ \\
\hline No depression (0-49) & $28(96.6)$ & $23(100.0)$ & 51 (98.1) \\
\hline Mild depression (50-59) & $1(3.4)$ & $0(0.0)$ & $1(1.9)$ \\
\hline Moderate depression (60-69) & $0(0.0)$ & $0(0.0)$ & $0(0.0)$ \\
\hline Severe depression $(\geq 70)$ & $0(0.0)$ & $0(0.0)$ & $0(0.0)$ \\
\hline General level of happiness $(n=52)$ & $7.2 \pm 1.9$ & $7.3 \pm 1.7$ & $7.2 \pm 1.8$ \\
\hline
\end{tabular}


way to make oneself and his/her spouse happy or satisfied $(n=7)$. The various ways to express sexuality included the following: intercourse $(n=41 ;$ males $=23$, females $=18)$, hugging/ kissing ( $\mathrm{n}=18$; males $=5$, females=13), masturbation ( $n=10$; males $=9$, female $=1$ ), and taking care of each other/ companionship $(\mathrm{n}=10$; males $=4$, females $=6$ ).

Majority of stroke survivors (89.7\%) showed positive attitude towards sexual intercourse. Likewise, most of the sexual partners (87.0\%) considered sexual intercourse as an important aspect of their relationship. Majority of stroke patients (55.2\%) and spouses (69.6\%) expressed fear of recurrence of stroke due to sex. Majority of both groups claimed that they were willing to participate in sexual intercourse and were able to discuss sexual issues openly with their partner. However, it was observed that those who were unable to openly discuss sexual matters with partner were either depressed and/or sexually dissatisfied.

Sexual intercourse was generally resumed between $4.9 \pm 7.6$ months and $6.1 \pm 8.8$ months after stroke (Table 2). Thirteen out of 52 participants claimed that they never resumed sexual intercourse.

Before stroke, majority had high libido (Table 2). After stroke, there was a significant decline in libido among stroke survivors and partners. Based on t-test for paired samples, there was a significant difference in the frequency of monthly coitus before and after stroke among patients $(\mathrm{p}<0.001)$ and partners $(\mathrm{p}<0.05)$. This statistically significant decline was attributed to the following factors in descending order of frequency: (1) effects of stroke (spasticity, pain, weakness, impaired balance, limited endurance, and difficulties in bed mobility and transitions), (2) aging, (3) lack of interest in sex or settled for companionship, (4) lack of self-esteem or body image issues, and (5) impaired erection or premature ejaculation.

In terms of arousal, we explored the effect of stroke on erection or ejaculation for males, and vaginal lubrication or orgasm for females. It was found that all male stroke survivors did not have any problem with erection or ejaculation prior to stroke. However, $52.6 \%$ of them had decreased arousal after stroke, and 10.5\% reported to have had no erection since then (Table 2). Such concern has never been raised or addressed in any prior medical consultation since the stroke, as reported by the participants. Likewise, majority of male or female sexual partners showed decline in arousal.

Negative attitude towards sex (Fisher's exact test: $\mathrm{p}<0.05,95 \%$ CI: $0.0,0.6726)$, inability to discuss sexual issues with partner (chi-square test: $\mathrm{p}<0.05$, OR: 0.2702, $95 \%$ CI: $0.0718,0.9128$ ), and unwillingness to participate in sexual intercourse (Fisher's exact test: $\mathrm{p}<0.01,95 \%$ CI: 0.0, 0.534 ) were significantly associated with lesser frequency of intercourse. The association of coital frequency with fear of recurrence of stroke and psychological disposition failed to reach statistical significance.

Lastly, sexual dissatisfaction post-stroke was prevalent in $59.6 \%$ of participants (Table 3). Among male patients and partners, 18 out of 27 were sexually dissatisfied (66.7\%) (Table 1). On the other hand, 13 out of 25 female participants were sexually dissatisfied (52\%). After subgroup analysis according to sex and whether they were stroke survivors

Table 2. Sexual functioning before and after stroke

\begin{tabular}{|c|c|c|c|c|}
\hline \multirow[b]{2}{*}{ Sexual Functioning Outcomes } & \multicolumn{2}{|c|}{ Pre-Stroke } & \multicolumn{2}{|c|}{ Post-Stroke } \\
\hline & $\begin{array}{l}\text { Patient } \\
(\mathrm{n}=29)\end{array}$ & $\begin{array}{l}\text { Partner } \\
(\mathrm{n}=23)\end{array}$ & $\begin{array}{l}\text { Patient } \\
(\mathrm{n}=29)\end{array}$ & $\begin{array}{l}\text { Partner } \\
(\mathrm{n}=23)\end{array}$ \\
\hline \multirow{2}{*}{ Time of resumption of sexual intercourse, mos. } & \multirow{2}{*}{ N/A } & \multirow{2}{*}{ N/A } & $4.9 \pm 7.6$ & $6.1 \pm 8.8$ \\
\hline & & & \multicolumn{2}{|c|}{$5.42 \pm 8.09\left(p=0.6003^{*}\right)$} \\
\hline $\begin{array}{l}\text { 1. Libido } \\
\text { High } \\
\text { Low } \\
\text { No libido } \\
\text { No change }\end{array}$ & $\begin{array}{c}22(75.9) \\
7(24.1) \\
0(0.0) \\
\text { N/A }\end{array}$ & $\begin{array}{c}16(69.6) \\
7(30.4) \\
0(0.0) \\
\text { N/A }\end{array}$ & $\begin{array}{c}2(6.9) \\
22(75.9) \\
1(3.4) \\
4(13.8) \\
\end{array}$ & $\begin{array}{c}0(0.0) \\
15(65.2) \\
3(13.1) \\
5(21.7) \\
\end{array}$ \\
\hline $\begin{array}{l}\text { 2. Monthly coital frequency } \\
\text { Mean } \pm \text { S.D. } \\
\text { Range } \\
\text { p-value }\end{array}$ & $\begin{array}{c}16.9 \pm 19.1 \\
1-90 \\
N / A\end{array}$ & $\begin{array}{c}15.8 \pm 20.9 \\
2-90 \\
\text { N/A }\end{array}$ & $\begin{array}{c}3.7 \pm 6.2 \\
0-30 \\
p=0.0008^{* *}\end{array}$ & $\begin{array}{c}3.7 \pm 6.7 \\
0-30 \\
p=0.0113^{* *}\end{array}$ \\
\hline $\begin{array}{l}\text { 3. Erection/ejaculation ( } \mathrm{n}=27 \text { males) } \\
\text { Normal/no change } \\
\text { Decreased } \\
\text { No erection }\end{array}$ & $\begin{array}{c}\mathrm{n}=19 \\
19 \\
0 \\
0\end{array}$ & $\begin{array}{c}n=8 \\
7 \\
1 \\
0\end{array}$ & $\begin{array}{c}\mathrm{n}=19 \\
7 \\
10 \\
2\end{array}$ & $\begin{array}{c}n=8 \\
1 \\
6 \\
1\end{array}$ \\
\hline $\begin{array}{l}\text { 4. Vaginal lubrication/orgasm ( } \mathrm{n}=25 \text { females) } \\
\text { Normal/no change } \\
\text { Decreased } \\
\text { No orgasm }\end{array}$ & $\begin{array}{l}\mathrm{n}=10 \\
8 \\
2 \\
0\end{array}$ & $\begin{array}{c}\mathrm{n}=15 \\
11 \\
4 \\
0\end{array}$ & $\begin{array}{c}\mathrm{n}=10 \\
4 \\
6 \\
0\end{array}$ & $\begin{array}{l}\mathrm{n}=15 \\
5 \\
8 \\
2\end{array}$ \\
\hline $\begin{array}{l}\text { 5. Sexual satisfaction } \\
\text { Satisfied } \\
\text { Dissatisfied } \\
\end{array}$ & $\begin{array}{c}28(96.6) \\
1(3.4) \\
\end{array}$ & $\begin{array}{c}21(91.3) \\
2(8.7) \\
\end{array}$ & $\begin{array}{l}12(41.4) \\
17(58.6) \\
\end{array}$ & $\begin{array}{l}10(43.5) \\
13(56.5) \\
\end{array}$ \\
\hline
\end{tabular}

${ }^{*} t$-test for independent samples. ${ }^{* *}$-test for paired samples. 
Table 3. Psychosocial factors and sexual satisfaction

\begin{tabular}{|c|c|c|c|c|}
\hline Psychosocial Factors & Sexually Satisfied & Sexually Dissatisfied & $p$-value & OR $(95 \% \mathrm{Cl})$ \\
\hline $\begin{array}{l}\text { General attitude toward sexual inter } \\
\text { Important }(n=46) \\
\text { Not important }(n=6) \\
\end{array}$ & $\begin{array}{l}20(43.5) \\
1(16.7)\end{array}$ & $\begin{array}{c}26(56.5) \\
5(83.3) \\
\end{array}$ & $p=0.2084^{*}$ & $3.763(0.4741,95.77)$ \\
\hline $\begin{array}{l}\text { Fear of recurrence of stroke } \\
\text { Yes }(n=32) \\
\text { No }(n=20) \\
\end{array}$ & $\begin{array}{r}12(37.5) \\
9(45.0) \\
\end{array}$ & $\begin{array}{l}20(62.5) \\
11(55.0)\end{array}$ & $\mathrm{p}=0.5918^{* *}$ & $0.7378(0.231,2.357)$ \\
\hline $\begin{array}{l}\text { Ability to discuss sexual issues with } \\
\begin{array}{l}\text { Yes }(n=33) \\
\text { No }(n=19)\end{array}\end{array}$ & $\begin{array}{c}17(51.5) \\
4(21.1)\end{array}$ & $\begin{array}{l}16(48.5) \\
15(78.9)\end{array}$ & $\mathrm{p}=0.0311^{* *}$ & $3.88(1.09,16.17)$ \\
\hline $\begin{array}{l}\text { Willingness to participate in sexual in } \\
\begin{array}{l}\text { Yes }(n=45) \\
\text { No }(n=7)\end{array}\end{array}$ & $\begin{array}{c}20(44.4) \\
1(14.3) \\
\end{array}$ & $\begin{array}{l}25(55.6) \\
6(85.7)\end{array}$ & $p=0.1304^{*}$ & $4.681(0.6239,116.3)$ \\
\hline $\begin{array}{l}\text { Psychological disposition } \\
\text { Zung's Depression Scale score }\end{array}$ & $32.7 \pm 7.7$ & $37.4 \pm 8.0$ & $\mathrm{p}=0.0399^{\wedge}$ & $\mathrm{N} / \mathrm{A}$ \\
\hline All participants $(\mathrm{N}=52)$ & $21(40.4)$ & $31(59.6)$ & $\mathrm{N} / \mathrm{A}$ & $\mathrm{N} / \mathrm{A}$ \\
\hline
\end{tabular}

${ }^{*}$ Fisher's exact test. ${ }^{* *}$ Chi-square. ${ }^{\wedge}$ t-test for independent samples.

or partners, females reported greater sexual satisfaction post-stroke than males; but this did not reach statistical significance $(p>0.05)$. Nevertheless, female stroke patients had the highest mean sexual satisfaction score (6.1 out of 10), followed by female partners (4.7), male partners (4.6), and male stroke patients (3.9). Factors significantly associated with sexual dissatisfaction were inability to discuss sexual concerns with partner $(\mathrm{p}<0.05)$ and depression $(\mathrm{p}<0.05)$ (Table 3). The level of happiness was moderately and positively correlated with the degree of sexual satisfaction (Pearson's correlation coefficient: $r=0.5096$ ).

\section{DISCUSSION}

Our study was able to document the statistically significant decline in coital frequency post-stroke among patients and their partners. Majority of participants had lower level of libido, sexual arousal, and sexual satisfaction after stroke. Participants who were unable to discuss sexual issues with their partner and who were depressed based on Zung's depression scale had greater chances to be sexually dissatisfied. Level of happiness was moderately and directly correlated with sexual satisfaction.

The present study recognized the various definitions of sexuality among participants, even considering differences in sex. Especially for females, sexuality transcended beyond physical pleasure, such that emotional bond through companionship and concern for one another were deemed more important. In contrast, there were more male participants who limited sexuality to the actual act of sexual intercourse. A meta-analysis by Oliver et al. reported data on sex differences across 21 different measures of sexual attitudes and behaviors. ${ }^{14}$ The most profound sex difference was observed in the incidence of masturbation, where men had significantly greater incidence. Another large gender difference was found in terms of attitudes toward casual sex, where males had significantly more permissive attitudes, while females had negative attitudes about it. Nevertheless, the meta-analysis found no difference in gender in terms of sexual satisfaction, which is consistent with the results of our study.

Another strength of the present study includes its attempt to explore the agreement between the responses of stroke survivors and their partners. There was no significant difference between the reports of patients and partners in terms of coital frequency and the time to resume sexual intercourse after stroke. Furthermore, the present study attempted to establish associations between psychosocial factors and changes in sexual functioning. It seemed that post-stroke sexual dissatisfaction was associated with the lack of openness or difficulties in discussing sexual issues with partner, and the degree of depression, as measured by Zung's self-rating depression scale. These findings were consistent with the study of Korpelainen. ${ }^{5}$

The study, however, was limited to exploring psychosocial factors as cause of sexual dysfunction. We, therefore, suggest that future quantitative studies analyze the effect of type and site of brain lesion, co-morbidities (such as diabetes and pre-existing psychopathy), and medications (such as anti-depressants and antihypertensives) on sexual functioning through subgroup analyses. Results of the study would have been more generalizable had it met its minimum sample size.

Being a complex human phenomenon, sexuality encompasses a broad spectrum of physical, emotional, psychological, social, and even spiritual behavior or disposition. ${ }^{15-16} \mathrm{~A}$ person's expression of sexuality is inherently affected by physical disability, emotional disposition (i.e., individual perceptions on sexuality), psychological distress, social taboos and infrastructure (i.e., barriers to privacy and mobility, such as when sharing the same bedroom with other people, and physical setup not friendly to people with disability), and religious beliefs (i.e., sexual intercourse is solely for procreation). ${ }^{15-19}$ 
Assessment of altered sexual health should be as important as evaluating other areas of human function. Unfortunately, concerns in sexuality among patients and their partners rarely receive attention in routine medical consultations in our setting. Reasons include the inability of the patients/ partners and the physicians to recognize the loss or decline that occurs in various aspects of sexual functioning, the difficulties in overcoming anxieties in sex-related discussions, and lack of confidence to identify problems and explore solutions..$^{20-21}$

The findings obtained from this study reflect poststroke sexual dilemmas of couples, which remain embedded in profound relationship changes, reversal of roles, and unmet expectations. Hence, the study strongly suggests the development of sexual rehabilitation programs for stroke patients and partners. These programs can include delivery of sexual health seminars and workshops to educate patients, partners, and healthcare providers on the effects of stroke on sexual functioning, and concrete ways on how to evaluate and address them accordingly.

In conclusion, the present study provided baseline local data on changes in sexual functioning that some stroke survivors and their partners have been suffering from. These changes, particularly the decline in coital frequency among others (decline in libido, sexual arousal, and sexual satisfaction), were significantly associated with psychosocial factors, such as negative attitude towards sexual intercourse, inability to discuss sexual matters, and unwillingness to participate in sex. A comprehensive stroke management that includes sexual rehabilitation to facilitate the closest return to pre-morbid state should be provided for couples afflicted by stroke.

\section{Acknowledgments}

The authors would like to thank Dr. Antonio C. Sison of the Department of Psychiatry, Philippine General Hospital, University of the Philippines Manila, and the Stroke Support Group of the Department of Rehabilitation Medicine for their invaluable contribution to the study.

\section{Statement of Authorship}

All authors have reviewed and approved the final version of this paper.

\section{Author Disclosure}

All authors declared no conflicts of interest.

\section{Funding Source}

This paper was funded by the primary investigator.

\section{REFERENCES}

1. The Stroke Society of the Philippines. SSP handbook of stroke: Guidelines for prevention, treatment, and rehabilitation, 6th ed. Quezon City, Philippines: Golden Pages Publishing Company, 2014.

2. Philippine Academy of Rehabilitation Medicine (PARM) [Internet]. PARM Clinical Practice Guidelines on Stroke Rehabilitation. 2011 [cited 2014 Sep]. Available from http://parm.com.ph/wp-content/ uploads/2016/09/PARM-Stroke-Rehabilitation-CPG-2011-1.pdf.

3. Caswell J. Sex and intimacy after stroke. Stroke connection. Mar-Apr 2009;12-15.

4. Monga TN, Lawson JS, Inglis J. Sexual dysfunction in stroke patients. Arch Phys Med Rehabil. 1986; 67(1):19-22.

5. Korpelainen JT, Nieminen P, Myllyla VV. Sexual functioning among stroke patients and their spouses. Stroke. 1999; 30(4):715-9.

6. Loo KW, Gan SH. Burden of stroke in the Philippines. Int J Stroke. 2013; 8(2):131-4.

7. Giaquinto S, Buzzelli S, Di Francesco L, Nolfe G. Evaluation of sexual changes after stroke. J Clin Psychiatry. 2003; 64(3):302-7.

8. Mojica JAP, Nario ARL, Cipriaso VAJ, et al. How much functional recovery is there in post-stroke patients? Acta Med Philipp. 1993; 29:220-4.

9. Agrell B, Dehlin O. Comparison of six depression rating scales in geriatric stroke patients. Stroke. 1989; 20(9):1190-4.

10. Abdel-Khalek AM. Measuring happiness with a single-item scale. Social behavior and personality. 2006; 34(2):139-50.

11. La Rosa MR, Ignacio S. The impact of stroke support group membership on quality of life, depression and happiness among stroke patients of the Philippine General Hospital. Residents' Research Protocols. 2011-2012. Department of Rehabilitation Medicine Philippine General Hospital University of the Philippines, Manila.

12. Schmitz MA, Finkelstein M. Perspectives on poststroke sexual issues and rehabilitation needs. Top Stroke Rehabil. 2010;17(3):204-13.

13. Armitage P, Berry G. In: Statistical Methods in Medical Research, 3rd ed. Oxford: Blackwell Scientific Publications; 1994. pp. 312-41.

14. Oliver MB, Hyde JS. Gender differences in sexuality: a meta-analysis. Psychol Bull. 1993; 114(1):29-51.

15. Masters WH, Johnson VE. Human sexual response. New York: Bantam Books.

16. Tracy D, Cataldo M. Sexuality: Behavior versus identity. HIV Counselor Perspectives. 2001;10(5).

17. Sanders SA, Hill BJ, Yarber WL, Graham CA, Crosby RA, Milhausen RR. Misclassification bias: diversity in conceptualisations about having 'had sex.' Sex Health. 2010; 7(1):31-4.

18. Greenberg J, Bruess C, Conklin S. Exploring the dimensions of human sexuality. USA: Jones and Bartlett Publishers, 2010.

19. Chandler BJ, Brown S. Sex and relationship dysfunction in neurological disability. J Neurol Neurosurg Psychiatry. 1998; 65:877-80.

20. Seymour LM, Wolf TJ. Participation changes in sexual functioning after mild stroke. OTJR (Thorofare N J). 2014; 34(2):72-80.

21. Tamam Y, Tamam L, Akil E, Yasan A, Tamam B. Post-stroke sexual functioning in first stroke patients. Eur J Neurol. 2008; 15(7):660-6. 